\title{
Pyricularia Leaf Spot: A New Disease of Ornamental Plants of the Family Marantaceae
}

\author{
Athanassios C. Pappas, Professor, University of Thessaly, School of Agriculture Crop \& Animal Production Labo- \\ ratory of Plant Pathology, Pedion Areos, 38334 Volos, Greece; and Epaminondas J. Paplomatas, Senior Research \\ Scientist, Benaki Phytopathologcal Institute, 14561 Kifissia, Athens, Greece
}

\begin{abstract}
Pappas, A. C., and Paplomatas, E. J. 1998. Pyricularia leaf spot: A new disease of ornamental plants of the family Marantaceae. Plant Dis. 82:465-469.

A severe leaf spot disease incited by the fungus Pyricularia oryzae was identified on Ctenanthe oppenheimiana and C. setosa "Greystar." Primary symptoms on young leaves consisted of individual circular to slightly irregular pinpoint spots with white necrotic centers zonated by narrow brown-yellow halos. On mature leaves, extended necrotic areas resembling those caused by phytotoxicity were formed. Artificially inoculated leaves with a spore suspension of the isolated fungus from the above case showed symptoms after 3 to 4 days' incubation at $25^{\circ} \mathrm{C}$ and high humidity. Fungal isolates obtained from Ctenanthe plants of Brazilian origin were found to be highly pathogenic on various plants within the family Marantaceae when they were tested by an excised leaf assay method. By contrast, $P$. oryzae isolates obtained from rice plants grown in Greece caused either hypersensitivity or immune response symptoms in various Marantaceae. Analysis of esterase and lactate dehydrogenase isozymes showed different banding patterns for rice and Ctenanthe isolates of $P$. oryzae. Conditions of prolonged leaf wetness combined with prevailing high temperature and humidity favored the epidemic appearance of the Pyricularia leaf spot disease on glasshouse-grown plants during the summer months of 1995 in Greece.
\end{abstract}

Additional keywords: Ctenanthe oppenheimiana, Pyricularia oryzae

In May 1995, an unusual destructive spotting, resembling bacterial infection, was observed on the leaves of young Ctenanthe oppenheimiana (E. Morr.) K. Schum. and C. setosa Eichl. "Greystar" plants grown in a glasshouse in Magnissia County. The above plants had been imported into Greece from Brazil, via the Netherlands, a few weeks earlier. One year later (May 1996), the same spotting was observed on leaves of 8-month-old C. oppenheimiana plants in a glasshouse in Chania County on the island of Crete. Laboratory examination of diseased sample material, made at the Bacteriological Laboratory of the Benaki Phytopathological Institute, revealed the absence of phytopathogenic bacteria from the infected leaf tissues (P. Psallidas, personal communication).

Parasitic leaf spots on tropical plants in the family of Marantaceae are known to be caused by various fungi $(4,5,8)$. The most

Corresponding author: A. C. Pappas

Accepted for publication 17 January 1998.

Publication no. D-1998-0316-01R

This article is in the public domain and not copyrightable. It may be freely reprinted with customary crediting of the source. The American Phytopathological Society, 1998. serious and commonly occurring spotting is incited by Drechslera setariae (Sawada) M. B. Ellis (Anamorph Helminthosporium setariae Sawada; 16).

A recent preliminary report noted that Pyricularia oryzae Cavara was isolated from spotted leaves of $C$. oppenheimiana, and in artificial inoculations it was found pathogenic on the leaves of $C$. oppenheimiana and C. setosa (12).

This study presents a detailed description of the disease symptoms and reports the conditions under which this new Pyricularia leaf spot of Ctenanthe spp. was developed. The identity of the causal agent $P$. oryzae from Ctenanthe and its pathogenic ability to affect other ornamental plants within the family Marantaceae were also demonstrated in comparison with fungal isolates from rice plants.

\section{MATERIALS AND METHODS}

Symptomatology and disease diagnosis. The environmental conditions inside the greenhouse (temperature and relative humidity), were measured daily by the use of a thermohydrometer. The various symptoms of the disease process on naturally infected $C$. oppenheimiana and C. setosa plants were also recorded. For this, observations on diseased plants of the above species were taken in the glasshouse of Crocus Flora S.A. in Almyros, Magnissia
County, from early May to the end of June 1995. Plants having leaf necrotic spots in various stages of development were selected and transferred to the laboratory. Then, the plants were incubated in moist polyethylene bags for 24 to $48 \mathrm{~h}$ at room temperature to allow sporulation of the pathogen on the leaf lesions. Detached infected leaves were also incubated upside down in Petri dishes with moist filter paper, for the same purpose.

Isolation and identification of the causal agent. Twenty newly formed disease spots were excised from $C$. oppenheimiana leaves. The spots were immersed in absolute alcohol, surface sterilized in $0.5 \%$ sodium hypochlorite for $3 \mathrm{~min}$, rinsed three times in sterilized water, dried with sterilized filter paper, and plated onto potato dextrose agar (PDA) in Petri dishes. Following incubation for 3 days at $25^{\circ} \mathrm{C}$ in the dark, subcultures were made by transferring hyphal tips from the periphery of each colony onto malt extract agar (MEA). Subcultures were further incubated for 5 to 8 days under the same conditions, then exposed for 24 to $48 \mathrm{~h}$ to ultraviolet light to promote spore formation. The identification of the fungus species in question was made on the basis of its morphological characters (conidiophores, conidia). The "Key" text for the genera identification of imperfect fungi (3) and the descriptions presented in specific taxonomic books $(6,11)$ were employed for this purpose. Reference isolates of Pyricularia oryzae obtained from rice plants (Oryza sativa L.) were used for comparison.

Isozyme analysis. To investigate the origin of primary inoculum, the isozyme variation of Ctenanthe (Ct-4, Ct- $6, \mathrm{Ct}-7)$ and rice (R-4, R-6, R-9) isolates of $P$. oryzae, originating from Brazil and Greece, respectively, was compared. Isolates were grown in $100 \mathrm{ml}$ potato-sucrose broth (100 g potato and $10 \mathrm{~g}$ sucrose/1 liter water) in 250-ml Erlenmeyer flasks at $22^{\circ} \mathrm{C}$ for 1 week (10). Then, each sample was suction-filtered through Whatman no. 1 filter paper; the collected mycelia were frozen immediately and then lyophilized. For each isolate, $30 \mathrm{mg}$ freeze-dried mycelia were ground using a glass rod in an Eppendorf tube with $240 \mu \mathrm{l} \mathrm{STEB}$ extraction buffer $\left(0.2 \mathrm{~g} \mathrm{MgCl}_{2} \cdot 6 \mathrm{H}_{2} \mathrm{O}, 0.084 \mathrm{~g}\right.$ 
$\mathrm{NaHCO}_{3}, 0.0034 \mathrm{~g}$ NaEDTA, 0.24 g Trisbase, $100 \mu$ Triton $\mathrm{X}-100,10 \mathrm{~g}$ sucrose, $78.2 \mu \mathrm{l} \mathrm{b}$-mercaptoethanol, $2 \mathrm{mg}$ bromophenol blue, and up to $100 \mathrm{ml}$ distilled water; $\mathrm{pH}$ was adjusted to 8.0 with $\mathrm{HCl}$; 13). Tubes were kept on ice during processing of the samples. Ground mycelia were centrifuged at $10,000 \mathrm{rpm}$ for $20 \mathrm{~min}$ at $4{ }^{\circ} \mathrm{C}$ and collected supernatants were stored at $-20^{\circ} \mathrm{C}$ until analyzed.

Electrophoresis of samples was performed in nondenaturating polyacrylamide gels using the Mini-Protean II Electrophoresis apparatus (Bio-Rad Laboratories, Richmond, CA). In both the separating $(7.5 \%)$ and the stacking (4\%) gels, Triton $\mathrm{X}-100$ ( $2.35 \%$ and $2.5 \%$, respectively) was used instead of sodium dodecyl sulfate. For each sample, $20 \mu$ were loaded per well and the electrophoresis was run at $80 \mathrm{~V}$ until the dye-front reached the bottom of the gels.

Visualization of esterase (EC 3.1.1.1) isozymes on the gel was performed as follows: $0.04 \mathrm{~g} \alpha$-naphthyl acetate and $0.04 \mathrm{~g} \beta$-naphthyl acetate were dissolved in $4 \mathrm{ml} \mathrm{50 \%}$ acetone and poured into $100 \mathrm{ml}$ $0.01 \mathrm{M}$ Tris-buffer solution, $\mathrm{pH}$ 7.1. Then, $0.1 \mathrm{~g}$ Fast Blue RR salt was added and the solution was filtered through Whatman No 1 filter paper. For the bands to develop, gels were incubated at $37^{\circ} \mathrm{C}$ for $1 \mathrm{~h}$. Lactate dehydrogenase (EC 1.1.2.3) staining was done according to Shaw and Prasad (15). The stain was prepared by adding 50 mg NAD ${ }^{+}, 30 \mathrm{mg}$ nitro blue tetrazlium salt (NBT), $2 \mathrm{mg}$ phenazine methosulfate (PMS), $10 \mathrm{ml} 1 \mathrm{M}$ Na DL-lactate $\mathrm{pH} 7.0$ (substrate), $15 \mathrm{ml} 0.5 \mathrm{M}$ Tris- $\mathrm{HCl} \mathrm{pH} 7.1$, $70 \mathrm{ml} \mathrm{H}_{2} \mathrm{O}$, and $5 \mathrm{ml} 0.1 \mathrm{M} \mathrm{NaCN}$. The substrate (1 M DL-lactate $\mathrm{pH}$ 7.0) was prepared by adding $49 \mathrm{ml} 1 \mathrm{M}$ $\mathrm{Na}_{2} \mathrm{CO}_{3} \cdot \mathrm{H}_{2} \mathrm{O}$ and $10.6 \mathrm{ml} 85 \%$ DL-lactic acid. Distilled water was added to bring the final volume to $100 \mathrm{ml}$. The visualization of the bands was done after incubation for $1 \mathrm{~h}$ at $37^{\circ} \mathrm{C}$.

Pathogenicity tests and host range. Artificial inoculations on leaves of potted plants of C. oppenheimiana and C. setosa were made. Drops of a spore suspension of $P$. oryzae isolates, obtained by flooding with sterile water and rubbing 15-day-old cultures grown on MEA, were used as inoculum. Cultures in Petri dishes were first incubated for 13 days in the dark at $25^{\circ} \mathrm{C}$, then exposed for $48 \mathrm{~h}$ to ultraviolet radiation to induce abundant sporulation. Harvested spores were filtered through a double layer of cheese cloth and the resultant concentration was adjusted to $5 \times 10^{4}$ spores $/ \mathrm{ml}$. Three different isolates of the fungus from $C$. oppenheimiana $(\mathrm{Ct}-4, \mathrm{Ct}-6$, and Ct-7) were used in these experiments. Inoculations were carried out with a Pasteur pipette, by positioning 5 droplets of the conidial suspension on the lower leaf surface (hanging droplets) of young leaves of potted plants of the above species. Following inoculation, the plants were covered with moist polyethylene bags and kept in a growth chamber at 24 to $30^{\circ} \mathrm{C}$ and $12 \mathrm{~h}$ artificial light until disease symptoms appeared. Three plants per treatment (3 leaves per plant) were used as replicates. Control plants were inoculated with droplets of sterile water. To complete Koch's postulates, re-isolations of the fungus from the artificially inoculated leaves were made following the litigation previously described.

The virulence of $P$. oryzae isolates to 14 plant species within the family Marantaceae and 1 species within the closely related family Musaceae was tested on excised leaf blades, floated upside down on sterilized water in Petri dishes. Inoculations were made by pipetting 5 droplets of conidial suspension $\left(5 \times 10^{4}\right.$ spores $\left./ \mathrm{ml}\right)$ onto each leaf tissue. The tests were replicated three times. Control leaves were inoculated with sterile water droplets. Petri dishes were incubated under the same conditions described previously for potted plants. These tests were repeated three times by comparing the virulence of pair isolates, one from Ctenanthe and one from rice plants; Ct-4:R-4, Ct-6:R-6, and Ct7:R-9, respectively.

Seven days after the inoculation, the severity of infection was assessed on the basis of the percentage of inoculation points per leaf that developed symptoms in each of the following categories: $\mathrm{A}=$ wellformed, yellowish-white transparent lesions, 8 to $10 \mathrm{~mm}$ in diameter at the point of inoculation, covered with the fungus fructifications; $\mathrm{B}=$ light-green specks hardly distinguishable with the naked eye, 1 to $2 \mathrm{~mm}$ in diameter, scattered at the inoculation points; and $\mathrm{C}=$ no visible infection symptoms.

The percentage of inoculation points per leaf exhibiting each symptom category was recorded and analyzed using Tukey's multiple range test.

\section{RESULTS}

Symptomatology and disease development. On both $C$. oppenheimiana and $C$. setosa, initial symptoms of natural infections were individual circular to slightly irregular distinct spots 1 to $3 \mathrm{~mm}$ in diameter. These primary symptoms were usually located on one side of the blade of a partially unfolded new leaf. In transmitted light, the lesions showed white necrotic centers surrounded by well-defined, narrow, water-soaked, brown-yellow halos that rather resembled bacterial infection (Fig. 1A). On mature leaves, although many primary spots failed to develop beyond 3 to $8 \mathrm{~mm}$ in diameter, they became whitish and necrotic. Slightly extended, depressed, necrotic areas frequently were formed near the margins or near the base of the blade of spotted leaves. These latter symptoms resembled phytotoxicity caused by fertilization or chemical spray applications (Fig. 1B). Severely infected young plants showed symptoms of distortion and dryness of the lower foliage, growth retardation, and finally death.

Infection symptoms were obvious before the young leaves were fully expanded. Mature leaves within the plant canopy were also prone to infection, but sporulation was observed only on newly formed spots when the relative humidity or leaf wetness was continuously high for at least $24 \mathrm{~h}$. Mature lesions on fully expanded
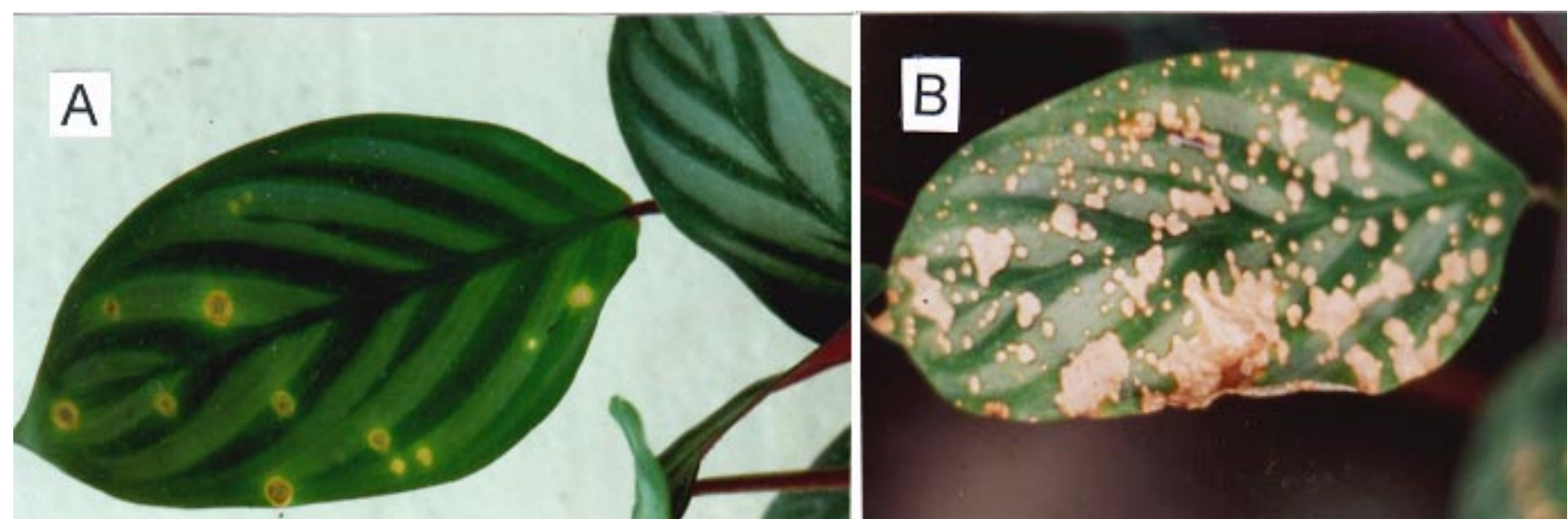

Fig. 1. Disease symptoms caused by Pyricularia oryzae on Ctenanthe oppenheimiana. (A) Primary infection lesions; (B) mature leaf showing extended necrosis. 
leaves usually turned into non-sporulating white-necrotic spots, restricted to their former dimensions. Infection spots were observed in scatter on the foliage of older Ctenanthe plants grown in the same glasshouse, not long after the introduction of the diseased young plant material. Samples of spotted leaves incubated in moist chambers for 24 to $48 \mathrm{~h}$ developed a fluff-like grayish mold consisting of conidiophores and conidia identical to those of P. oryzae.

Thirty days after the import and transplanting of the diseased young plants (to the end of May), the total number of spotted leaves on plants in the glasshouse was very limited. The disease developed and disseminated rapidly during the first half of June. The conditions prevailing at this period included mean day and night time temperatures of 25 and $20^{\circ} \mathrm{C}$, respectively; day and night relative humidity of 50 to $75 \%$ and 90 to $100 \%$, respectively; and prolonged maintenance of leaf wetness (because of the frequent application of overhead mist during the day).

Causal organism. Colonies of the isolated fungus $P$. oryzae from Ctenanthe on PDA or MEA media in Petri dishes were composed of thin, dense, slow-growing mycelium reaching about $30 \mathrm{~mm}$ in diameter after incubation for 6 days at $25^{\circ} \mathrm{C}$ in the dark. The amount of aerial hyphae was rather limited, and the color of the colony was white-grayish on the upper side and dark brown to black on the bottom side of the Petri dishes. Sporulation was moderate, but it was enhanced when developed cultures were exposed to ultraviolet light.

Figure 2 (A,B,C,D), shows the morphological characteristics (conidiophores and conidia) of the isolated fungus. A detailed description was given in the preliminary report by Pappas and Vloutoglou (12).

Pathogenicity and host range susceptibility. All of the artificially inoculated $C$. oppenheimiana and $C$. setosa plants exhibited symptoms of infection 4 days after inoculation when they were incubated at continually high moisture at 25 to $30^{\circ} \mathrm{C}$. Chlorotic transparent lesions, 5 to $7 \mathrm{~mm}$ in diameter with brown-white centers and yellow halos, developed at most of the inoculation points. Following an additional 2 days of incubation, sporulation occurred on the lower surface of the diseased lesions. In sampled isolations made from infected sites 4 days after the artificial inoculation, $P$. oryzae was constantly reisolated on PDA media. All of the control plants, inoculated with water drops and maintained under the same conditions, remained symptomless.

Out of 14 plant species within the family of Marantaceae and 1 species within the family Musaceae (banana) tested, 9 developed symptoms of infection when they were inoculated with $P$. oryzae isolates from $C$. oppenheimiana and evaluated by the leaf bioassay method. However, a variation in severity of disease symptoms among the different plant species was observed. The results presented in Table 1 show the degree of susceptibility of various host species to $\mathrm{Ct}-7$ isolate from $\mathrm{Cten}$ anthe and to R-9 isolate from rice plants. Similar results were obtained when other pair isolates from Ctenanthe and rice plants were used as inoculum. In the 6 host-plants (e.g., C. oppenheimiana) highly susceptible to Ctenanthe isolate, yellowishwhite transparent lesions 8 to $10 \mathrm{~mm}$ in diameter (category A), were visible 3 days fructifications developed following a further 2 days of incubation. In 3 species of after inoculation. The characteristic fungal

Marantaceae (e.g., Calathea insignis) moderately resistant to the above isolate, very minute light-green, non-sporulating specks hardly visible to the naked eye (category B) were formed at the inoculation points (hypersensitivity response); Musa sapientum responded similarly. In the remaining 5 resistant species of Marantaceae (e.g., Calathea lietzei), the leaf tissues inoculated with the Ctenanthe isolate, and in all cases of inoculation with water droplets, no symptoms of infection developed (category C).

Inoculations with $P$. oryzae isolates from rice caused only hypersensitivity response
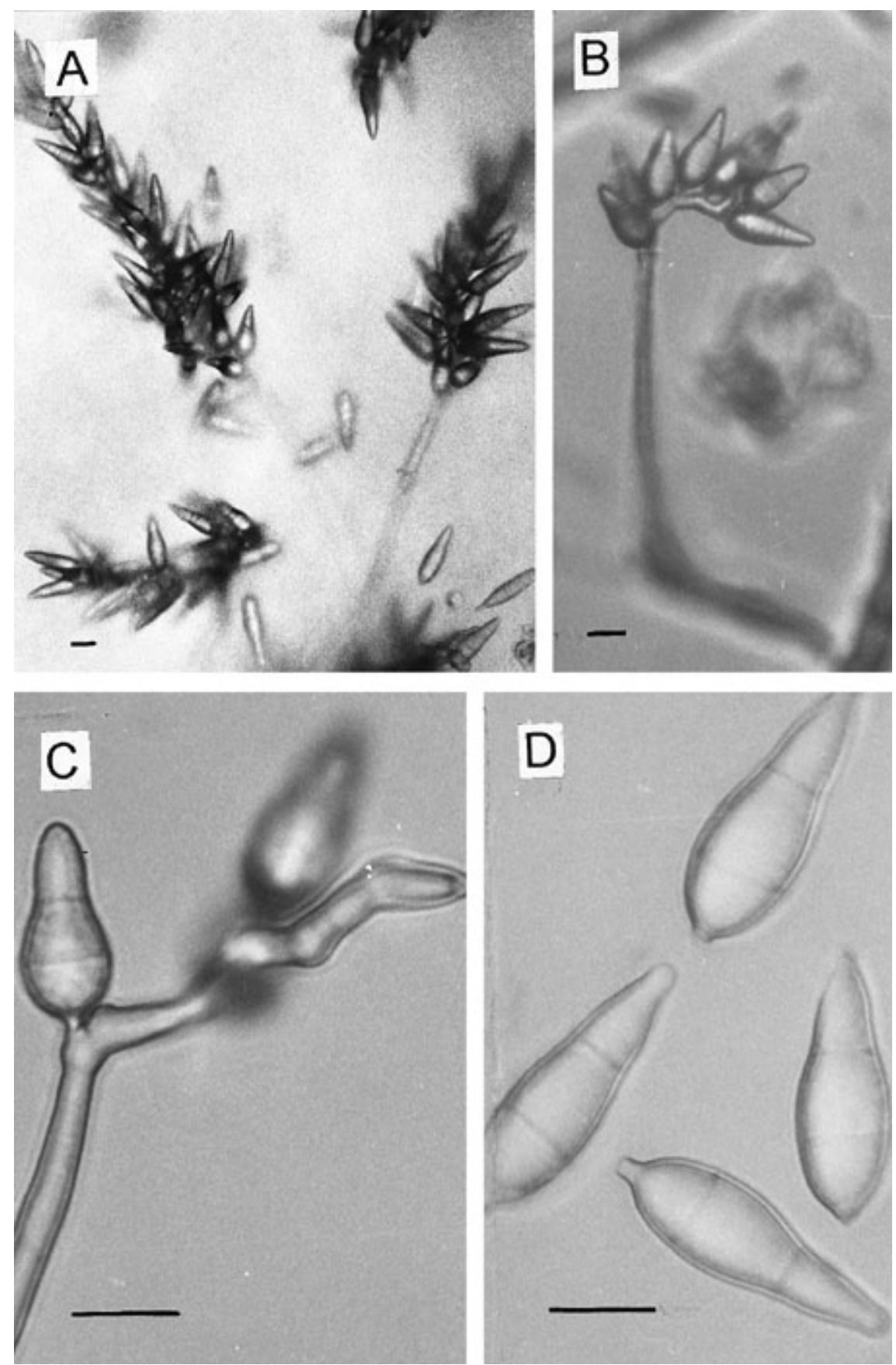

Fig. 2. Morphological characteristics of Pyricularia oryzae (Ctenanthe isolate) from culture on malt extract agar. Conidiophores with conidia: (A) 200×; (B) 400×; (C) 1,000×. (D) Conidia, 1,000×. Reference bar $=10 \mu \mathrm{m}$. 
on 6 out of 14 plant species of Marantaceae (category B) while all of the remaining inoculated species continued to be without symptoms of infection (category C; Table 1).

Isozyme patterns. Isozymes analysis for esterase showed different patterns of bands between Ctenanthe isolates and rice isolates; polymorphism was evident within rice isolates. Isozyme patterns for lactate dehydrogenase was similar for all three Ctenanthe isolates and clearly differentiated from those of rice isolates.

\section{DISCUSSION}

From the data presented in this work, it is evident that the isolated fungus $P$. oryzae from $C$. oppenheimiana, is a new pathogen for plants of the family Marantaceae, causing a destructive leaf spot disease. Severe symptoms of extended necrosis, usually observed on the spotted leaves, were presumably due to the pathogen's toxins. Similar symptoms are caused by pathogenic races of $P$. oryzae on susceptible rice cultivars. Fujita et al. (9) showed that the toxin(s) that are released during spore germination of this organism are responsible for such phytotoxicity symptoms on host plants.

Magnaporthe grisea (Hebbert) Barr., the perfect stage of $P$. oryzae Cav. (= P. grisea Sacc.), is well known as an important pathogen on $O$. sativa, causing the destructive rice blast disease. Races with different physiological and morphological characteristics were reported to infect mainly plants within the family of Gramineae, whereas plants from other families have occasionally been reported as the pathogen's hosts (11).

Great variation in fungus spore dimensions, cultural characteristics, and host specificity is recognized among different isolates originating from various hosts. Moreover, environmental factors, such as moisture and the growth substrate, greatly affect the morphology of the fungus $(1,11)$. Due to this diversity in the species traits and the simultaneous use of both anamorph names, great confusion exists in the literature about the identity of the fungus. Because of this, Asuyama (2) proposed that only the well-established name $P$. oryzae be used, and that the species be subdivided into specialized forms, according to their host specificity. This proposal was adopted later by others, following the recognition of the existence of a considerable number of pathogenic races by the use of differential rice cultivars (11). In contrast to those proposals, Rossman et al. (14) reported that only the name of $P$. grisea should be used for the anamorph stage, according to the International Code of Botanical Nomenclature. Because of these controversial aspects, and the fact that the fungus isolated from Ctenanthe was identical to the fungus from rice that was used for comparison, we propose that the well-established $P$. oryzae name to be used for our isolate.

P. oryzae (Ctenanthe isolate) was found to be virulent on many members of the Marantaceae family and the closely related Musaceae family. However, only 2 Calathea species (C. amabilis and C. ornata), 2 species of Ctenanthe ( $C$. oppenheimiana and C. setosa), Maranta leuconeura, and Stromanthe sanguinea appeared highly susceptible to the isolates from Ctenanthe. The other 3 infected species of Marantaceae (Calathea insignis, C. rufibarba, and Ctenanthe pilosa), and Musa sapientum of Musaceae, exhibited hypersensitivity response to such inoculum. On the other hand, no single species of Marantaceae was found to be susceptible to the fungal isolates from rice plants. A limited number of species belonging to the genera of $\mathrm{Ca}$ lathea and Maranta exhibited moderate resistance and all the remaining ones were immune. These results contribute to the suggestion of the existence in $P$. oryzae of highly pathogenic forms specialized to infect plants within the family Marantaceae. Further cross-pathogenicity studies on rice differential cultivars and more detailed analysis of pathogenic variability should be done to reduce the threat of dissemination and introduction of new races into rice-growing areas with the worldwide distribution of such ornamentals. Nevertheless, the discovery of hypersensitivity and immune response of various Marantaceae plants to $P$. oryzae inoculation reveals the existence of a gene or genes in plant species of this family which confer resistance against the disease. The isolation and possible transfer of such genetic material into rice cultivars may contribute considerably to the control of the devastating rice blast disease.

On the basis of the pathogenicity tests and the isozyme analysis, a clear differentiation between $P$. oryzae isolates from Ctenanthe (Brazilian origin) and those from rice plants (Greek origin) seems to occur. These data provide strong evidence that the primary inoculum of this new disease was transmitted with the imported Ctenanthe plant material. This, followed by the long daily duration of the leaf wetness in combination with the predominance of high temperature and relative humidity in the glasshouse, seems to have caused the rapid development of the disease during the first half of June 1995. Under these conditions, the incubation period of the

Table 1. Development of symptoms in artificial inoculations by Pyricularia oryzae isolates from Ctenanthe (Ct-7) and rice (R-9) plants on leaves on selected species in the families Marantaceae and Musaceae

\begin{tabular}{|c|c|c|c|c|c|c|}
\hline \multirow[b]{3}{*}{ Host species } & \multicolumn{6}{|c|}{ Percentage of inoculation points with infection symptoms } \\
\hline & \multicolumn{3}{|c|}{ Ctenanthe-isolate } & \multicolumn{3}{|c|}{ Rice-isolate } \\
\hline & $\mathbf{A}^{\mathbf{x}}$ & B & $\mathbf{C}$ & $\mathbf{A}$ & B & $\mathbf{C}$ \\
\hline Calathea amabilis E. Morr. & $100 \mathrm{~b}^{\mathrm{y}}$ & $0 \mathrm{a}$ & $0 \mathrm{a}$ & $0 \mathrm{a}$ & $73 \mathrm{~b}$ & $27 \mathrm{a}$ \\
\hline Calathea insignis Petersen & $0 \mathrm{a}$ & $100 \mathrm{c}$ & $0 \mathrm{a}$ & $0 \mathrm{a}$ & $100 \mathrm{~b}$ & $0 \mathrm{a}$ \\
\hline Calathea lietzei E. Morr. "Greenstar" & $0 \mathrm{a}$ & $0 \mathrm{a}$ & $100 \mathrm{c}$ & $0 \mathrm{a}$ & $0 \mathrm{a}$ & $100 \mathrm{~b}$ \\
\hline Calathea makoyana E. Morr. & $0 \mathrm{a}$ & $0 \mathrm{a}$ & $100 \mathrm{c}$ & $0 \mathrm{a}$ & $0 \mathrm{a}$ & $100 \mathrm{~b}$ \\
\hline Calathea ornata Koern. "Sanderiana" & $93 \mathrm{~b}$ & $7 \mathrm{a}$ & $0 \mathrm{a}$ & $0 \mathrm{a}$ & $80 \mathrm{~b}$ & $20 \mathrm{a}$ \\
\hline Calathea rufibarba Fenzl. "Wavestar" & $0 \mathrm{a}$ & $73 \mathrm{~b}$ & $27 \mathrm{~b}$ & $0 \mathrm{a}$ & $20 \mathrm{a}$ & $80 \mathrm{~b}$ \\
\hline Calathea veitchiana Veitch. & $0 \mathrm{a}$ & $0 \mathrm{a}$ & $100 \mathrm{c}$ & $0 \mathrm{a}$ & $100 \mathrm{~b}$ & $0 \mathrm{a}$ \\
\hline Calathea sp. "Freddie" & $0 \mathrm{a}$ & $0 \mathrm{a}$ & $100 \mathrm{c}$ & $0 \mathrm{a}$ & $0 \mathrm{a}$ & $100 \mathrm{~b}$ \\
\hline Calathea sp. "Misto" & $0 \mathrm{a}$ & $0 \mathrm{a}$ & $100 \mathrm{c}$ & $0 \mathrm{a}$ & $0 \mathrm{a}$ & $100 \mathrm{~b}$ \\
\hline Ctenanthe oppenheimiana (E. Morr.) K. Schum. & $100 \mathrm{~b}$ & $0 \mathrm{a}$ & $0 \mathrm{a}$ & $0 \mathrm{a}$ & $0 \mathrm{a}$ & $100 \mathrm{~b}$ \\
\hline Ctenanthe pilosa Eichl. "Golden mosaic" & $0 \mathrm{a}$ & $100 \mathrm{c}$ & $0 \mathrm{a}$ & $0 \mathrm{a}$ & $0 \mathrm{a}$ & $100 \mathrm{~b}$ \\
\hline Ctenanthe setosa Eichl. "Greystar" & $100 \mathrm{~b}$ & $0 \mathrm{a}$ & $0 \mathrm{a}$ & $0 \mathrm{a}$ & $0 \mathrm{a}$ & $100 \mathrm{~b}$ \\
\hline Maranta leuconeura E. Morr. "Fascinator" & $100 \mathrm{~b}$ & $0 \mathrm{a}$ & $0 \mathrm{a}$ & $0 \mathrm{a}$ & $100 \mathrm{~b}$ & $0 \mathrm{a}$ \\
\hline Musa sapientum Kuntze & $0 \mathrm{a}$ & $100 \mathrm{c}$ & $0 \mathrm{a}$ & $0 \mathrm{a}$ & $0 \mathrm{a}$ & $100 \mathrm{~b}$ \\
\hline Stromanthe sanguinea Sonder "Stripestar" & $100 \mathrm{~b}$ & $0 \mathrm{a}$ & $0 \mathrm{a}$ & $0 \mathrm{a}$ & $0 \mathrm{a}$ & $100 \mathrm{~b}$ \\
\hline S.E.D. ${ }^{\mathrm{z}}$ & 2.43 & 7.04 & 6.44 & 0.00 & 7.53 & 7.53 \\
\hline
\end{tabular}

x A = well-formed, yellowish-white, transparent lesions at inoculation point, covered with the fungal fructifications; $\mathrm{B}=$ light-green specks hardly distin-

guishable with naked eye at the point of inoculation; $\mathrm{C}=$ no visible symptoms of infection.

y Data within a column followed by the same letters do not differ significantly $(P<0.05)$, according to Tukey's multiple range test.

z S.E.D. = standard error of difference. 
disease did not exceed 3 to 4 days. Similarly, rice blast epidemics occur when relatively high temperatures (around $20^{\circ} \mathrm{C}$ ) prevail at night, alternating with day temperature of 30 to $35^{\circ} \mathrm{C}$ (17). Conidia are produced on rice leaf lesions only when the relative humidity is maintained above 93\%. Moreover, the long duration of free water on leaf surfaces seems to be a necessary factor for spore release, discharge, and germination of $P$. oryzae $(7,11)$.

Marantaceae family members require high moisture conditions for a proper commercial cultivation in glasshouses; otherwise, the margins of their leaves appear burned or they become easily infested by mites. Because moisture is a limiting factor in dry and hot Mediterranean regions, overhead irrigation is applied frequently during summer days. This cultural practice was highly conducive to the initiation and development of a destructive epidemic of Pyricularia leaf spot within glasshouses in Greece. Unrolling new leaves were prone to infection by the fungus, due to the water retained inside the long, hollow cylinder formed by each new leaf. Mature leaves within the plant canopy were also vulnerable, presumably because they remained wet for more extended periods.

The identification of the P. oryzae Cav. isolate from Ctenanthe was confirmed by P. M. Kirk, International Mycological Institute. Voucher cultures have been placed at the International Mycological Institute (Code IMI 369635) and at the American
Type Culture Collection (Code 200217, 200218, and 20019). Specimens of diseased material were placed at the Herbarium of Systemic Botany and Mycology Laboratory, Beltsville, Maryland (Code 737599 and 737600).

\section{ACKNOWLEDGMENTS}

We thank P. Psallidas from the Benaki Phytopathological Institute, Laboratory of Bacteriology, for examining diseased plants of Ctenanthe spp. and determining that infection by phytopathogenic bacteria was not the cause of the observed symptoms. We also thank Crocus Flora S.A. for providing research facilities for this project and covering the publication cost of this paper.

\section{LITERATURE CITED}

1. Arase, S., Katano, Y., Li, X., Honda, Y., and Nozu, M. 1994. Morphological variation in spores of Pyricularia oryzae Cavara. J. Phytopathol. 142:253-257.

2. Asuyama, H. 1965. Morphology, taxonomy, host range, and life cycle of Pyricularia oryzae. Pages 9-22 in: Proc. Rice Blast Dis. Symp. Int. Rice Res. Inst. Maryland. Johns Hopkins Press, Baltimore.

3. Barnett, H. L., and Hunter, B. B. 1987. Illustrated Genera of Imperfect Fungi. Macmillan Publishing Co., New York.

4. Chase, A. R. 1988. Compendium of ornamental foliage plant diseases. American Phytopathological Society Press, St. Paul, MN.

5. Da-Silva M., and Minter, D. W. 1995. Fungi from Brazil: recorded by Batista and coworkers. Mycological Paper No 169. CAB International Mycological Institute, Kew Surrey, U.K.

6. Ellis, M. B. 1971. Dematiaceous Hyphomycetes. Commonwealth Mycological Institute, Kew Surrey, U.K.

7. El Refaei, M. I. 1977. Epidemiology of rice blast disease in the tropics with special reference to the leaf wetness in relation to disease development. Indian Agricultural Research Institute, Ph.D. thesis. New Delhi, India.

8. Farr, D. F., Bills, G. F., Chamuris, G. P., and Rossman, A. Y. 1989. Fungi on plants and plant products in the United States. American Phytopathological Society Press, St. Paul, MN.

9. Fujita, K., Arase, S., Hiratsuka, H., Honda, Y., and Nozu, M. 1994. The role of toxin(s) produced be germinating spores of Pyricularia oryzae in pathogenesis. J. Phytopathol. 142:245-252.

10. Leung, H., and Williams, P. H. 1986. Enzyme polymorphism and genetic differentiation among geographic isolates of the rice blast fungus. Phytopathology 76:778-783.

11. Ou, S. H. 1985. Rice Diseases. Commonwealth Agricultural Bureau, Slough U.K.

12. Pappas, A. C., and Vloutoglou, I. 1996. First report of a new leaf spot disease of Ctenanthe caused by Pyricularia oryzae. Plant Dis. 80:463.

13. Rivillas, C., and Dodd, J. C. 1996. The effects of arbuscular mycorrhizal fungi on two different coffee varieties from Colombia and their biochemical detection in roots. Pages 47-50 in: Proc. 4th Eur. Symp. Mycorrhizas, Granada, Spain.

14. Rossman, A. Y., Howard, R. J., and Valent, B. 1990. Pyricularia grisea, the correct name for the rice blast disease fungus. Mycologia 82:509-512.

15. Shaw, C. R., and Prasad, R. 1970. Starch gel electrophoresis of enzymes- a compilation of recipes. Biochem. Genet. 4:297-320.

16. Simone, G. W. 1983. New leaf spot disease of Calathea and Maranta spp. incited by Drechslera setariae. Plant Dis. 67:1160-1161.

17. Subramanian, C. V. 1968. Pyricularia oryzae. C.M.I. Descriptions of Pathogenic Fungi and Bacteria, No 169. Commonwealth Mycological Institute, Kew Surrey, U.K. 